\title{
ETNOGRAFIA NA RODOVIÁRIA: FLUXOS E TRAJETÓRIAS SOCIAIS EM UM ESPAÇO COSMOPOLITA
}

\author{
Fernanda Rechenberg \\ Cornelia Eckert e Ana Luiza Rocha (Orientação)
}

A proposta deste ensaio é pensar a rodoviária como um espaço de encontro cosmopolita, refletindo acerca das idéias de cosmopolitismo de Gustavo Lins Ribeiro, Ulf Hannerz e Marshall Sahlins. O cosmopolitismo é aqui estudado a partir de depoimentos de trabalhadores da rodoviária, que já passaram por um processo migratório ou que são permanentemente atravessados por deslocamentos e portanto, por diferentes culturas, ethos e visões de mundo

Pensar a rodoviária como um espaço cosmopolita requer uma abordagem singular da noção de cosmopolitismo, ou ainda requer explicitar o termo para tentar justificar sua utilização na etnografia de um espaço como a rodoviária. Ulf Hannerz (1990), em artigo sobre cosmopolitas e locais, menciona a mudança na concepção de cosmopolitismo ao longo de diferentes décadas, citando um estudo de Robert Merton em que este aponta na Segunda Guerra Mundial o sujeito cosmopolita como aquele que ultrapassava os limites da localidade na qual habitava, vivendo inserido em uma estrutura de nação. Hoje, segundo Hannerz, é a integração internacional que determina a universalidade. Uma cultura mundial é criada através de um entrelaçamento de culturas locais diversificadas, sem o apoio nítido de um território específico. Para o autor, a idéia de cosmopolitismo não está necessariamente e unicamente ligada ao deslocamento concreto, mas antes, a um estado mental, uma forma de administrar o significado que revela uma orientação e uma forma de se envolver com o Outro.

A preocupação de Hannerz em precisar o que é ou não cosmopolita limita a proposta deste trabalho se for seguida à risca. Isso porque a rodoviária acolhe pessoas com diferentes rotas e motivações de deslocamento; ao se pensar um espaço - e não um grupo social - como cosmopolita, corre-se o risco de ampliar demais o conceito de cosmopolitismo, incluindo trajetórias pessoais de deslocamento que não necessariamente se enquadram na proposta de Hannerz, que prevê no processo cosmopolita uma alteração profunda das estruturas de significado (1990:252). O 
cosmopolita, segundo o autor, precisaria relacionar-se com uma pluralidade de culturas consideradas entidades distintas, familiarizando-se com estas (1990:253). Se para Hannerz o verdadeiro cosmopolita não negocia com a outra cultura, mas aceitaa como um todo, adoto aqui uma posição negociada com o próprio autor, relativizando sua noção de cosmopolitismo, aceitando algumas de suas proposições e recusando outras. Para o caso de meu universo de pesquisa - a rodoviária de Porto Alegre - acredito que é o agenciamento a forma de contato cultural adotada pelos informantes que apresento neste trabalho.

Assim, mais vale apropriar-me da noção de cosmopolitismo como um estado mental de abertura à cultura do Outro, mesmo tendo em mente a insuficiência desta pesquisa para responder sobre o estado mental cosmopolita dos viajantes, trabalhadores e freqüentadores da rodoviária. De qualquer forma, a relação destas pessoas com o deslocamento (de si ou do Outro) incorpora, se não uma abertura consciente à cultura do outro, uma inevitável convivência. Neste sentido, a rodoviária é percebida como um lugar de encontro de diferentes trajetórias sociais e mesmo culturas, que se deslocam ou se constituem no próprio deslocamento e na incorporação da diferença.

A idéia de uma etnografia no espaço da rodoviária inspira-se na proposta de James Clifford (1997) de pensar o campo em termos de fluxo e não como um lugar espacialmente determinado. Em artigo que critica a concepção clássica de campo em antropologia e a supressão do encontro etnográfico nos relatos, Clifford aponta os perigos de se confundir a noção localizada de campo com a idéia de cultura, problematizando a delimitação do campo no tempo e espaço. De modo geral, o que fica de fora dos relatos antropológicos é justamente o amplo mundo global de importações e exportações interculturais no qual o encontro etnográfico está imerso.

O que está em jogo, na proposta de Clifford, é a própria concepção de cultura, na medida em que questiona a idéia de cultura como um corpo enraizado que cresce, vive e morre. Historicidades construídas e disputadas, lugares de deslocamento, interferência e interação são idéias mais adequadas a esta nova proposta. Nesta perspectiva, uma série de atores sociais que ficaram marginalizados dos relatos etnográficos por não caberem em uma concepção mais fechada de cultura, podem vir à tona: é o caso dos missionários, peregrinos, turistas, criados, mercadores, mixedblood, etc. 
Para o caso deste estudo, elaborado a partir da etnografia de um espaço que alude ao deslocamento e inserido em uma grande cidade, trago em mente os escritos de Simmel (1967) sobre a vida na metrópole, que para o autor se caracteriza pela agregação de pessoas com diferentes interesses, integrando suas relações e atividades em um organismo altamente complexo, que é a cidade. O intenso intercâmbio social na metrópole traz a idéia de trocas culturais e a impossibilidade de se pensar a cidade como campo isolado.

$\mathrm{Na}$ linha do que Clifford aponta ao entender a cultura no próprio deslocamento, Ulf Hannerz, desconstrói a idéia de local como tipo ideal no estudo das culturas, entendendo as mesmas como vinculadas a interações e relações sociais que não restritas a limites territoriais - culturas relacionadas por redes amplas em termos espaciais. Assim, podemos pensar que as culturas misturam-se e sobrepõemse em espaços concretos - ou mesmo no deslocamento. A rodoviária vem a ser um destes espaços de encontros da vida social contemporânea, que, por oferecer ligação terrestre com diferentes cidades, estados e países, oportuniza uma experiência de intercâmbio cultural e de estilos de vida.

\section{Sociedades complexas e trajetórias sociais na rodoviária}

Refletindo sobre a rodoviária de Porto Alegre como um espaço inserido em uma sociedade complexa (VELHO:1994) que é a cidade, é possível pensar a partir da definição de Gilberto Velho a própria rodoviária como um espaço representativo de uma sociedade complexa moderno-contemporânea dentro da cidade. Segundo este autor, um dos aspectos que caracteriza as sociedades complexas é a existência de heterogeneidade cultural, no sentido da coexistência de uma pluralidade de tradições com bases étnicas, ocupacionais, religiosas, etc, que dão origem a um intenso processo de interação entre grupos e segmentos diferenciados, associados a uma permanente troca cultural através de migrações e viagens.

As noções de projeto e campo de possibilidades deste autor nos ajudam a compreender não só o fenômeno da migração, que encontra na rodoviária um de seus espaços principais, mas das trajetórias de indivíduos e/ou grupos sociais no interior de uma mesma sociedade. A rodoviária, como um lugar de trocas e encontros, é repleta de trajetórias e biografias emblemáticas de um quadro sócio-histórico e 
cultural. A migração de cidades do interior para a capital, tão corrente nas falas dos trabalhadores da rodoviária, revela um projeto de ascensão social.

A maioria aqui na rodoviária. São vários do interior aqui ... que vieram e ficaram. (...) Eu sei que eu vim pequeninho. Com a roupinha tudo suja de bolo frito (risos). Fazer bolinho frito naquelas rodas de carreta, assim, numa frigideira. É meu amigo, isso aí não tenho vergonha de dizer. (...). Me criei caçando de bodoque. Aqui dizem funda, né, mas eu chamava de bodoque. Caçando mas pra comer, né, nunca botei fora uma, caçava e matava pra comer. E pescando na beira do rio peixe, chegava naquelas tapera...aqueles campo bonito assim, porque lá todo mundo se conhecia, né, então tu podia entrar nas propriedades, caçar e coisa, conhecia o dono, tudo, não tinha problema, então era liberado...aí tinha aquelas tapera, laranja, bergamota, tudo que era fruta, tu chegava e comia à vontade, não tinha problema. Fome não se passava nunca. Aí sempre foi, até o dia de hoje é pobre né, a gente é pobre mas...lá era mais pobre ainda, então...mas fome não se passava. Sempre tinha fruta, sempre tinha tudo. Só a gente não tinha um chinelo, um sapato pra botar, sempre de pé descalço...se tivesse era um parzinho só pra ti ir numa festa, numa coisa. Geralmente tinha aquelas festas de igreja...aí tu ia, guardava pra ir pra festa. Mas, a maioria andava de pé descalço na lavoura, no milho, no soja, carpindo, cortando...e assim vai, né. E a vida ensina muito...a gente aprende muito, dia a dia, amadurece..

Jair, caixa de lancheria

$\mathrm{O}$ ato e a possibilidade de escolha dos indivíduos, em oposição à determinação do grupo, são o ponto de partida para a formulação de um projeto. Os projetos, ainda que reconhecidos como individuais, são construídos a partir de experiências sócio-culturais, elaborados a partir do que Gilberto Velho denomina campo de possibilidades, ou seja, um recorte circunscrito histórica e culturalmente. Falar de projeto individual no contexto de sociedades complexas requer a consciência da interpenetração de diferentes mundos e a fluidez das fronteiras culturais. Nesta perspectiva, a construção de um projeto social se constituiria pela vivência de interesses comuns, reunindo membros de uma mesma classe social, grupo étnico, religião, vizinhança e mesmo família. 
Este trabalhador de uma lancheria na rodoviária, descreve a semelhança de seu projeto individual com a trajetória de seus irmãos mais velhos, que já haviam abandonado o lugar de origem para tentar a sorte em Porto Alegre.

Eu era pequeno, tu vê, tinha sete anos...seis, sete anos eu trabalhava na lavoura com o pai direto...carpia, era as lavoura de milho e coisa...era só eu o pai e a mãe porque os outros irmão tudo aqui em Porto Alegre, tudo pra cá com quinze anos...então é assim.

Vieram estudar ou vieram já tentar...

Não, vieram trabalhar, já ficaram tudo aqui na rodoviária, eu tô aqui porque eles tudo trabalharam na rodoviária também...aí agora eles foram e eu fiquei. Um foi pra Mato Grosso, outros foram pra outros lugares e quem restou fui eu, eu sou o mais novo, né, são cinco homens.

Mas eles trabalharam aqui mesmo?

Todos. Não, um trabalhou aqui, o outro ali na Tio Patinhas, o outro lá em cima no Gulla lá, e outro lá naquela pequeninha lá. E eu trabalhei naquele pequeninha ali, na Tio Patinhas também e aqui.

Jair, caixa de lancheria

Mesmo com um projeto comum, a singularidade de cada trajetória e de cada projeto inserido em um campo de possibilidades delineou diferentes rumos para estes irmãos. A partir dos comentários de Gilberto Velho sobre projeto individual, é possível compreender uma inicial semelhança nos projetos de membros de uma mesma família, que tendem a se diferenciar na medida das especificidades de cada um, bem como da originalidade das experiências em sua trajetória na capital. Nesta perspectiva, defrontamo-nos com a complexidade e a diversidade de trajetórias delineadas a partir do encontro com o espaço, ou o campo de possibilidades representado pela rodoviária como porta de entrada de uma "cidade grande". A idéia de dinamicidade dos projetos, ou seja, de sua possibilidade de transformação frente à ação de outros sujeitos e às mudanças sócio-históricas também nos ajuda a compreender a diversidade nas trajetórias dos irmãos.

\section{Lugar de origem e lugar de morada}

A terra natal quando, vista da perspectiva da metrópole, é em muitos casos idealizada como um lugar onde os perigos e o lado negativo (impessoalidade, 
pobreza, violência) da grande cidade não existem. Marshall Sahlins, em artigo que reflete sobre os processos migratórios da população samoana, fala desta idealização como produto ideológico do sistema intercultural (1997:12). As idéias de que "lá todo mundo se conhecia, e fome não se passava nunca", presentes nos relatos, reforçam a visão da terra natal como um lugar onde sobrevive um estilo de vida tradicional. Para Sahlins, as visões respectivas que os setores moderno e tradicional têm um do outro mantém a circulação entre eles.

O não retorno à terra natal e a constituição de uma nova família na metrópole, como no caso de Jair, aponta para aquilo que Sahlins denomina as "vantagens da cidade" (1997:10), e que exprime uma assimetria complementar presente na sociedade transcultural, onde o setor moderno desfruta de certa superioridade. A alta divisão econômica de trabalho, a variedade diversificada de serviços e a proposta de liberdade individual (Simmel: 1967), fazem da metrópole um espaço de atração.

Sahlins também utiliza a idéia de "ampliação do mundo", referindo-se ao acesso conquistado pelos samoanos aos produtos de uma divisão de trabalho internacional. Trazendo esta idéia para uma escala diminuta, podemos associar a migração dos interioranos para a capital, tomando esta como um centro cosmopolita, a uma forma de conquista de novas possibilidades de trabalho e estilos de vida. A rodoviária de Porto Alegre reúne muitos relatos e apresenta de maneira concreta a circulação de pessoas que tem na capital o lugar de destino de uma viagem que contém em si a expectativa de mudança ou ascensão social.

As possibilidades almejadas pelos migrantes nem sempre se concretizam, como nos informa o relato de dois taxistas que acompanham diariamente o movimento da rodoviária.

É, aqui circula muita gente, aqui tem muita gente boa mas também tem muito sem vergonha. Eu uma vez aqui peguei um rapaz aí que ele...ele é de Itaqui. Ele veio de um lugar aí com dinheiro no bolso, os cara assaltaram ele, levaram ele. Fazia três dia que ele não comia tava comendo só pão do lixo. Aí eu mandei botar uma janta pra ele aí e falei com o Precioso, e o Precioso arrumou uma passagem pra ele ir pra Itaqui. Bah, o cara se...chorava e...foi embora. Paguei a janta pra ele aí. Um prato de comida não faz falta pra gente, um pouco a mais...

Rios, taxista noturno 
A gente compra muita passagem aí. Pessoal vem pra cá, eles roubam eles, vêm perdido aí...Tinha um que tva aí foi o ano passado agora, ele veio pra cá e roubaram, assaltaram ele, ele ficou aí. No natal ele tava aí mendindo ali, aí fui conversar com ele, daí eu vi que não era, que o cara era até trabalhador. Pedi onde ele morava, era longe. Passagem dele dava 40 e poucos pila...quarenta e dois. Mas ele tava mendigo, não tem nem como subir num ônibus. Aí fui em casa, moro lá em Viamão, peguei roupa, trouxe roupa pra ele...e levei ele pra tomar um banho, comprei uma passagem pra ele, foi embora bem faceiro...bah! Quando ele subiu no ônibus ele ficou numa faceirice!

Tem muita gente que tu olha assim às vezes mendigo tu pensa que...fica mendigo porque vem pra cá não tem como ir embora mais.

Carlos, taxista noturno

A face ameaçadora de uma grande cidade pode ter suas feições amenizadas pela constituição de redes de parentesco e pelo movimento de pessoas circulando entre a terra natal e a atual morada. Sahlins aponta a existência de uma constante circulação de pessoas, direitos e cuidados, como um sistema de relações sociais calcado na comunidade de origem que atravessa as percepções de diferença e isolamento características do processo de migração.

Para Sahlins, existem culturas translocais que, à semelhança dos povos de Samoa, vem se desenvolvendo em países do terceiro mundo, "entre povos supostamente encarcerados pelo imperialismo e sem nenhuma esperança de 'desenvolvimento'”(1997:7). Estes movimentos, para o autor, atuam como postos avançados de bases rurais tribais, criando junto com a aldeia de origem, uma relação mútua de sustentação. Na perspectiva de uma continuidade entre os mundos rural e urbano, ou o que poderíamos chamar de lugar de origem e lugar de morada, uma população translocal, é capaz de habitar ambos os mundos, e mantê-los como partes interdependentes de uma totalidade sociocultural. A idéia de um campo social comum, não territorial, onde rural e urbano compartilham valores, sistemas sociais e mesmo aspectos econômicos, permite aproximar os setores metropolitano e interiorano, tornando-os cada vez mais semelhantes entre si. Sahlins cita o trabalho de Keith Hart na década de 60 entre os Frafra rurais e urbanos, onde a autora oferece 
uma perspectiva que transcende a oposição entre moderno e tradicional, apresentando a idéia de uma "expansão dos horizontes da comunidade" (apud Sahlins, 1997:9). Esta expansão faz com que o campo ou lugar de origem tenha acesso e compartilhe com a cidade valores, sistemas econômicos e sociais, tornando cada vez mais difícil manter a tradicional dicotomia entre rural e urbano.

É interessante pontuar aqui a insistência de Sahlins em afirmar que estas sociedades translocais têm seu foco culturalmente orientado na terra natal, contrapondo à idéia de uma desterritorialização ou de uma ligação meramente simbólica ou imaginária destes grupos/pessoas com seus lugares de origem. De qualquer forma, os processos migratórios estão sempre associados a processos de enraizamento e desenraizamento que supõem, se não um desligamento da cultura e do lugar de origem, como mostra Sahlins, uma transformação dos aspectos culturais até então muitas vezes sentidos como a forma possível de organização social.

\section{$O$ aspecto acolhedor do deslocamento}

O lado acolhedor da metrópole também é ressaltado por este taxista, que explica a migração para a cidade, aludindo também à vinda de moças de outros estados:

\footnotetext{
Maior parte são as gurias de fora que vem pra cá e elas imigram aqui e não querem voltar mais...o gaúcho tem o coração muito quente, né...gaúcho é muito...muito amoroso, então as gurias vêm pra cá não querem voltar mais. Encontram aqui esta beleza, aonde tem lugar pra dançar, aonde tem lugar pra jantar, onde tem pra confraternizar com os amigos, então elas não querem mais voltar
}

Rios, taxista noturno

É interessante notar que a rodoviária não é apenas um lugar significativo para se pensar os deslocamentos atuais, mas também os passados. Na conversa com informantes que vieram do interior e hoje trabalham neste espaço, percebe-se um acúmulo de tempos e gestos de deslocamento, revelados nos diferentes lugares de origem destas pessoas e nos diferentes momentos em que chegaram em Porto Alegre. Muitos vieram do interior e encontraram na rodoviária um espaço de trabalho. 
Como portal do lugar de destino e para muitos o primeiro lugar de contato em uma cidade grande, é comum ouvir de trabalhadores (donos de bar, carregadores, etc) uma vinculação estreita com o hábito da viagem que os levou a trabalhar neste reduto "cosmopolita" da cidade. Observando que de todos os trabalhadores entrevistados na rodoviária, nenhum era natural de Porto Alegre, temos aí algum subsídio para acreditar que a rodoviária é, de alguma forma, um lugar de acolhimento. Um acolhimento, entretanto, não territorializado, mas essencialmente cosmopolita: as pessoas que ali trabalham têm de alguma forma uma relação estreita com a viagem, o deslocamento, a diversidade. Por ali circulam diariamente pessoas de diferentes lugares, que falam diferentes línguas, sotaques e dialetos. Entre os entrevistados, um carregador de malas deu a seguinte explicação para o fato de trabalhar ali:

Ah, eu vim parar aqui porque eu corria muito trecho, a Dona Encrenca lá pediu pra mim dar uma...parar de viajar, aí eu entrei na rodoviária pra não viajar mais, só carrego viajante agora (risos). Agora eu vejo os outros viajar.

\section{Diferentes cosmopolitismos?}

Gustavo Lins Ribeiro, em "Pós Imperialismo - Cultura e Política no Mundo Contemporâneo" sublinha que o sentimento e o fenômeno cosmopolita não se restringe ao mundo ocidental, e tampouco é uma representação social de elite. Para o autor, os intensos movimentos migratórios globais dos últimos séculos aumentaram a quantidade de pessoas desenraizadas, complexas segmentações étnicas nacionais e urbanas, redes transnacionais e culturas diaspóricas que, entremeadas com os efeitos dos meios de massa, criaram um cosmopolitismo popular e alimentaram processos e visões de globalização. Os fluxos de globalização popular existem há muitos séculos, haja vista a antiga e constante circulação de marinheiros, prostitutas, escravos (RIBEIRO:2003); ou ainda missionários, mercadores, peregrinos, policiais (CLIFFORD: 1997). Assim, Ribeiro pontua a coexistência de cosmopolitismos que diferem entre si, como o correspondente aos fluxos populares, o acadêmico, de corporações internacionais, etc.

A idéia de um cosmopolitismo popular proposta por Ribeiro tenta reverter o fato por ele reconhecido de que o cosmopolitismo é uma categoria usualmente de 
elite, e que com freqüência alude à sofisticação resultante da familiaridade com o que é diferente. Essa idéia contrasta visivelmente com a delimitação do sujeito cosmopolita defendida por Hannerz. Sem querer aqui responder se existe ou não um cosmopolitismo popular, deixo em aberto o diálogo entre os dois autores e aproveito suas idéias para pensar um tipo de troca e intercâmbio social que é bastante antigo e acontece em paralelo aos deslocamentos cosmopolitas tal como são entendidos por Hannerz.

De qualquer forma, a migração e o deslocamento pressupõem um processo de enraizamento e desenraizamento que evoca a noção de pertencimento. Para Ribeiro, a habilidade de localizar a si próprio e aos outros em termos geográficos, culturais e políticos são cultural e historicamente construídas. Estas formas de representar pertencimento a unidades sócio-culturais e políticas, unindo pessoas a coletividades e territórios, podem ser concebidas como um continuum de círculos concêntricos, na perspectiva de uma integração do sistema mundial. Assim todos os níveis - local, regional, nacional, internacional e transnacional - se fazem presentes permitindo sentimentos de múltiplos pertencimentos.

Neste sentido, é possível pensar em uma certa familiaridade, no mundo contemporâneo, com o fato de pertencer a mais de um lugar ao mesmo tempo, o que também suaviza ou torna menos doloroso o dilema de pertencer à pequena cidade de origem ou à metrópole, atual lugar de morada.

\footnotetext{
Ah, sinto saudade, muita saudade, às vezes vem os...os...eu considero como irmão, não são meus irmãos, mas considero, me criei lá até os dez anos com eles...às vezes vêm aqui, aparecem, aí...eu tô até devendo, quero levar minha esposa meus filhos lá, pra conhecer, eles nunca foram, não conhecem...então...mas a saudade bate, né, bate .
}

Jair, caixa de lancheria 


\section{Fluxos e diversidade cultural}

A rodoviária e as pessoas que nela trabalham ou transitam, são constantemente atravessadas por fluxos regionais, nacionais e internacionais, dada a multiplicidade de destinos possíveis ali oferecidos. Isso quer dizer que, muitas vezes sem se deslocar para outro estado ou país, o trabalhador de um lugar como a rodoviária entra em contato com pessoas de diferentes culturas. Estar em uma metrópole amplia as possibilidades de contato com uma cultura global.

O relato do garçom de uma lanchonete da rodoviária apóia esta nossa hipótese:

No tempo que teve aí os nigeriano aí, quando teve o fórum esse da educação, né, tinha que ver o que entrou de...de negrão aqui, de crioulo. Era um sarro, sabe, daí eu

...eu não falo muito inglês, né, e eles falam...a maioria deles fala três línguas né, é o inglês, o francês que se fala lá na Nigéria né, e as língua nativa deles né, então não se entendia nada, uma hora eles falavam inglês, uma hora eles falavam em francês e outra hora eles falavam em dialeto, lá não sei quantos mil dialetos tem na África, ali naquela área deles ali né, várias tribo, então não se entendia coisa nenhuma né, quando eu tentava entender alguma coisa que eles falavam eles já trocavam já de novo.

Marcos, garçom de lancheria

Refletindo sobre os desdobramentos do que nos informa esse relato, podemos pensar na existência de níveis intermediários de compreensão das culturas estrangeiras, em um diálogo negociado com Hannerz a respeito do perfil cosmopolita. A partir de experiências rápidas de contato cultural destes trabalhadores da rodoviária, desenvolve-se, na linha do que Hannerz coloca como o estado mental cosmopolita, uma abertura à cultura do Outro. Mesmo sem saber se este contato altera ou não em profundidade as estruturas de significado destes trabalhadores, este estudo acredita que o contato acarreta pequenas transformações no cotidiano destas pessoas que, de uma forma ou outra, levam as vantagens de uma cultura global para o conjunto de experiências pessoais e de suas relações sociais. 


\section{REFERENCIAS}

CLIFFORD, James. Routes. Travel and Translation in the Late Twentieth Century. Cambridge: Harvard University Press, 1997.

HANNERZ, Ulf. Cosmopolitas e locais na cultura global. In: Featherstone, Mike. Cultura Global: nacionalismo, globalização e modernidade. Petrópolis: Editora Vozes, 1990.

RIBEIRO, Gustavo Lins. Cosmopoliticas. Postimperialismo. Cultura y Política em el mundo contemporâneo. Bracelona: Gedisa Editorial, 2003.

SAHLINS, Marshall. O pessimismo sentimental e a experiência etnográfica: por que a cultura não é um objeto em via de extinção (parte II). In: Mana, vol 3 n 2. Rio de Janeiro, 1997.

SIMMEL, Georg. A metrópole e a vida mental. In: Velho, Otávio Guilherme (org). O fenômeno urbano. Rio de Janeiro, 1967.

VELHO, Gilberto. Individualismo e Cultura. Rio de Janeiro: Jorge Zahar Editor, 1997.

VELHO, Gilberto. Projeto e Metamorfose: antropologia das sociedades complexas. Rio de Janeiro: Jorge Zahar Editor, 1994. 